\title{
Calculating the design effect for a cluster stepped-wedge trial with varying cluster size; a case study from a trial in type 2 diabetes
}

\author{
Nuzhat Ashra ${ }^{1,2^{*}}$, Melanie Davies ${ }^{1,2}$, Kamlesh Khunti ${ }^{1,2}$, Laura Gray ${ }^{2,3}$ \\ From 3rd International Clinical Trials Methodology Conference \\ Glasgow, UK. 16-17 November 2015
}

\section{Background}

Type 2 diabetes (T2DM) is a serious chronic disease which can be improved with education. Only $6.0 \%$ of people with T2DM are offered education and only $1.6 \%$ attend.

\section{Methods}

We have designed a cluster trial with a stepped-wedge design (SWD) to test an intervention to increase the uptake to education. This study will include general practices of varying size. There is no published guidance on powering a cluster SWD with varying cluster size. We present the method used to estimate the design effect (DE) which combines the method for calculating the sample size required for a cluster SWD by Woertman et al. with a method for taking into account varying cluster size in a standard cluster trial by Eldridge et al.

\section{Results}

We assume a median practice size of 347, IQR 201-678, which gives a Coefficient of Variation (CV) of 119.25/ $348=0.34$. Using the method of Woertman gives a DE of 1.41; this doesn't take into account variation in cluster size. Using the method in Eldridge with a CV of zero (no variation in cluster size) gave DE of 18.35; replacing $\mathrm{CV}$ with 0.34 gave DE of 20.36. Hence variation in cluster size inflates DE by 2.01 (20.36-18.35). The total DE therefore when taking into account the SWD and variation in cluster size was $3.42(1.41+2.01)$.

\section{Conclusion}

We present a pragmatic way of calculating the DE for cluster SWD with variation in cluster size. Future work should focus on the impact of cluster size variation.

${ }^{1}$ Diabetes Research Centre, University of Leicester, Leicester, UK

Full list of author information is available at the end of the article

\section{Authors' details}

${ }^{1}$ Diabetes Research Centre, University of Leicester, Leicester, UK. '2Leicester Clinical Trials Unit, University of Leicester, Leicester, UK. ${ }^{3}$ Department of Health Sciences, University of Leicester, Leicester, UK.

Published: 16 November 2015

doi:10.1186/1745-6215-16-S2-P124

Cite this article as: Ashra et al: Calculating the design effect for a cluster stepped-wedge trial with varying cluster size; a case study from a trial in type 2 diabetes. Trials 2015 16(Suppl 2):P124.
Submit your next manuscript to BioMed Central and take full advantage of:

- Convenient online submission

- Thorough peer review

- No space constraints or color figure charges

- Immediate publication on acceptance

- Inclusion in PubMed, CAS, Scopus and Google Scholar

- Research which is freely available for redistribution
C Biomed Central 